\title{
The severity of malnutrition among children with pneumonia and diarrhoea: moderate acute malnutrition- a neglected entity
}

\author{
Savitha M. ${ }^{1 *}$, Thanuja B. ${ }^{2}$
}

DOI: https://doi.org/10.17511/ijpr.2020.i02.06

1* M R Savitha, Professor, Department of Paediatrics, Mysore Medical College and Research Institute, Mysuru, Karnataka, India.

2 B. Thanuja, Postgraduate, Department of Paediatrics, Mysore Medical College and Research Institute, Mysuru, Karnataka, India.

Introduction: Acute malnutrition is a global health problem. In India, $38 \%$ of under-5 children are stunted, $21 \%$ are wasted and $36 \%$ are underweight. Prevalence in Karnataka of wasting is $26.1 \%$, Severe Acute Malnutrition (SAM) is $10.5 \%$ and that of diarrhoea and pneumonia is $4.5 \%$ and $1.2 \%$ respectively. Both SAM and Moderate Acute Malnutrition (MAM) have serious consequences. This study was undertaken to find the proportion of MAM among children with pneumonia and diarrhoea. Objectives: To study the prevalence and severity of malnutrition (SAM and MAM) among children admitted with pneumonia and acute diarrhoea. Methodology: Cross-sectional study of 97 children aged 1 month to 5 years admitted with pneumonia or acute diarrhoea were included. Anthropometry, treatment details and complications were recorded and analysed. Diagnosis of Pneumonia, diarrhoea, SAM and MAM was based on WHO guidelines. Results: More females were malnourished when compared to males. Prevalence of diarrhoea and pneumonia were the same among MAM and SAM children. Association of the severity of malnutrition with complications and with the duration of hospital stay was noted. Conclusions: Complications and morbidities in MAM are similar to SAM, hence, it is important to diagnose MAM and treat it vigilantly as in SAM. It is important to recognize and monitor MAM which may often go neglected.

Keywords: Moderate acute malnutrition, Severe acute malnutrition, Diarrhoea, Pneumonia

Corresponding Author

M R Savitha, Professor, Department of Paediatrics, Mysore Medical College and Research Institute, Mysuru, Karnataka, India.

Email: drprashu@gmail.com
How to Cite this Article

Savitha MR, Thanuja B. The severity of malnutrition among children with pneumonia and diarrhoea: moderate acute malnutrition- a neglected entity. Pediatric Rev Int J Pediatr Res. 2020;7(2):80-86. Available From

https://pediatrics.medresearch.in/index.php/ijpr/arti cle/view/570
To Browse

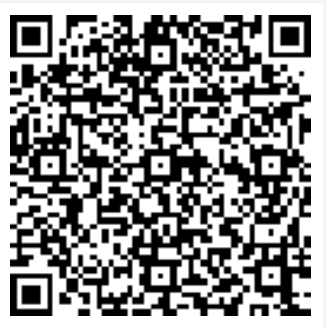

Manuscript Received 2020-02-10

Conflict of Interest No
Review Round 1 2020-02-20

Funding Nil
Review Round 2 2020-02-24

Ethical Approval Yes
Review Round 3

Accepted 2020-02-28

Plagiarism X-checker $9 \%$

(C) 2020 by M R Savitha, B. Thanuja and Published by Siddharth Health Research and Social Welfare Society. This is an Open Access article licensed under a Creative Commons Attribution 4.0 International License https://creativecommons.org/licenses/by/4.0/ unported [CC BY 4.0]. 


\section{Introduction}

Acute malnutrition is a major global health problem $[1,2]$. According to the World Health report, 52 million children under 5 years around the world, were classified as having acute malnutrition in 2012, of which 33 million children had moderate acute malnutrition (MAM). Hence, MAM affects one in ten children under 5 years of age in underdeveloped and developing countries.

According to NFHS- 4 , in India, $38 \%$ of under-5 children are stunted, suggestive of chronic undernutrition, $21 \%$ are wasted, which is a sign of acute undernutrition, while $36 \%$ are underweight [3].

There are significant regional variations in the prevalence of MAM. Prevalence of wasting in Karnataka is $26.1 \%$ and Severe Acute Malnutrition (SAM) is $10.5 \%$ [3]. One in six under-5 children in South Asia suffered from MAM in 2013. India has the highest-burden, with over 25 million children under 5 with MAM or SAM [1]. Prevalence of diarrhoea and pneumonia in Karnataka is $4.5 \%$ and $1.2 \%$ respectively [3]. Children with malnutrition, have roughly three times higher risk of mortality from common communicable diseases than if they were well-nourished.

Both SAM and MAM have serious consequences, contributing to increased morbidity and mortality and also impaired intellectual development, suboptimal adult work capacity and increased risk of disease in adulthood. Interventions to address undernutrition should, therefore, include a strong component of MAM management which is often neglected. As the present national programmes are focussed more on children with SAM, the present study was undertaken to find out the proportion of MAM amongst the two leading causes of under 5 mortality, namely pneumonia and diarrhoea.

\section{Objectives}

To study the prevalence and severity of malnutrition (SAM and MAM) amongst children (1 month to 5 years of age) admitted with community-acquired pneumonia and acute diarrhoea.

\section{Methodology}

01. Setting: Paediatrics ward, Cheluvamba Hospital (tertiary care teaching hospital), Mysuru, Karnataka.
01. Duration: a period of 6 months from March 2019 to August 2019

02. Type of study: cross-sectional study

03. Sampling method: Purposive sampling

04. Sample calculation: Sample size of 90 was calculated using the formula $\mathrm{n}=\mathrm{z} 2(\mathrm{pq}) / \mathrm{d} 2$ $[z=1.96, p=$ prevalence of diarrhoea $=4.5 \%$, prevalence of pneumonia $=1.2 \%[3], q=1-p$, $d=95 \%$ C.I. $]$.

05. Inclusion criteria: Children between 1 month and 5 years of age with community-acquired pneumonia or diarrhoea admitted to Cheluvamba hospital, Mysuru.

06. Exclusion criteria: Children with obvious secondary causes for malnutrition such as chronic illness or global developmental delay

07. Data collection procedure: A cross-sectional study of children between the age group of 1 month and 5 years who were admitted to Cheluvamba hospital from March 2019 to August 2019, with community-acquired pneumonia or acute diarrhoea was done. Anthropometry at the time of admission, treatment details and complications were recorded in a pre-designed study proforma.

08. Data analysis: On the basis of WHO guidelines the following were defined:

01. Diagnosis of 'Pneumonia' (fast breathing and/or chest indrawing) and 'severe pneumonia' (pneumonia with any danger sign) [4]. Diagnosis of diarrhoea: the passage of $>3$ loose stools/ day (or more frequent passage than is normal for the individual).

02. Diagnosis of SAM: 6 mon- 5 years: Weightfor-height (length) $<-3 \mathrm{SD}$ or Bilateral pitting pedal edema or MUAC $<11.5 \mathrm{~cm}$. $0-6$ mon: weight-for-length $<-3 S D$ or Bilateral pitting pedal edema [5].

03. Diagnosis of MAM: weight-for-height (length) between -2 to -3 SD or MUAC between 11.5$12.5 \mathrm{~cm} \mathrm{[6].}$

04. Anthropometry: Length was measured for $<2$-year age group using infantometer, height for 2-5year age group using a stadiometer, weight using electronic weighing scale (sensitive up-to $10 \mathrm{~g}$ ), (MUAC) Mid upper arm circumference ( $6 \mathrm{mon}-5$ year) using the cross-tape method in the nondominant arm. 
Weight-for-height used for diagnosis of SAM (<-3SD) and MAM ( -2 to -3 SD) was plotted as per WHO growth charts. Descriptive statistics like Frequency, Percent, Mean, Standard deviation and inferential statistics like Chi-square test, ANOVA test was used.

09. Ethical clearance: obtained from the institutional ethics committee

\section{Results}

Table-1: Gender distribution among the severity of malnutrition

\begin{tabular}{|l|l|l|l|}
\hline \multirow{2}{*}{} & \multicolumn{2}{|c|}{ Gender } & \multirow{2}{*}{ Total } \\
\cline { 2 - 3 } & Male (\%) & Female $(\%)$ & \\
\hline Normal & $43(70.5 \%)$ & $15(41.7 \%)$ & $58(59.8 \%)$ \\
\hline MAM & $9(14.75 \%)$ & $12(33.3 \%)$ & $21(21.65 \%)$ \\
\hline SAM & $9(14.75 \%)$ & $9(25 \%)$ & $18(18.55 \%)$ \\
\hline
\end{tabular}

More number of females were malnourished, and a greater number of males were well-nourished, which was statistically significant $(p=0.018)$

Table 2: Age distribution among the severity of malnutrition.

\begin{tabular}{|l|l|l|l|l|}
\hline \multirow{2}{*}{} & \multicolumn{3}{|c|}{ AGE } & \multirow{2}{*}{ Total } \\
\cline { 2 - 4 } & $<6$ months & $6-12$ months & $>12$ months & \\
\hline Normal & $9(15.5 \%)$ & $29(50 \%)$ & $20(34.5 \%)$ & 58 \\
\hline MAM & $0(0 \%)$ & $9(42.9 \%)$ & $12(57.1 \%)$ & 21 \\
\hline SAM & $0(0 \%)$ & $8(44.4 \%)$ & $10(55.6 \%)$ & 18 \\
\hline Total & $9(9.3 \%)$ & $46(47.4 \%)$ & $42(43.3 \%)$ & 97 \\
\hline
\end{tabular}

There was no statistically significant association between age and severity of malnutrition. ( $p$-value $0.065)$.

Table-3: Severity of diarrhoea versus severity of malnutrition.

\begin{tabular}{|l|l|l|l|l|l|}
\hline & \multicolumn{1}{|c|}{$\begin{array}{c}\text { No } \\
\text { diarrhoea }\end{array}$} & $\begin{array}{c}\text { No } \\
\text { dehydration }\end{array}$ & $\begin{array}{c}\text { Some } \\
\text { dehydration }\end{array}$ & $\begin{array}{c}\text { Severe } \\
\text { dehydration }\end{array}$ & Total \\
\hline Normal & $\begin{array}{l}39 \\
(67.2 \%)\end{array}$ & $3(5.2 \%)$ & $16(27.6 \%)$ & $0(0 \%)$ & 58 \\
\hline MAM & $\begin{array}{l}14 \\
(66.7 \%)\end{array}$ & $2(9.5 \%)$ & $4(19 \%)$ & $1(4.8 \%)$ & 21 \\
\hline SAM & $\begin{array}{l}13 \\
(72.2 \%)\end{array}$ & - & $5(27 \%)$ & $0(0 \%)$ & 18 \\
\hline Total & $66(68 \%)$ & $6(6.2 \%)$ & $24(24.7 \%)$ & $1(1 \%)$ & 97 \\
\hline
\end{tabular}

There was no statistically significant association between the severity of diarrhoea and malnutrition. ( $p$-value 0.586). Therefore the prevalence of diarrhoea was the same among both MAM and SAM children.
Table-4: Severity of pneumonia versus severity of malnutrition

\begin{tabular}{|l|l|l|l|l|}
\hline & Severe pneumonia & Pneumonia & No pneumonia & Total \\
\hline Normal & $2(3.4 \%)$ & $37(63.8 \%)$ & $19(32.8 \%)$ & 58 \\
\hline MAM & $1(4.8 \%)$ & $14(66.7 \%)$ & $6(28.6 \%)$ & 21 \\
\hline SAM & $1(5.6 \%)$ & $12(66.7 \%)$ & $5(27.8 \%)$ & 18 \\
\hline Total & 4 & 63 & 30 & 97 \\
\hline
\end{tabular}

There was no significant association between the severity of pneumonia and malnutrition.

Therefore the prevalence of pneumonia was the same among both MAM and SAM children.

Table 5: Complications among severity of malnutrition.

\begin{tabular}{|l|l|l|l|l|l|}
\hline & No complications & Empyema & \multicolumn{1}{|c|}{ Sepsis } & Tuberculosis & Total \\
\hline Normal & $57(98.3 \%)$ & $1(1.7 \%)$ & $0(0 \%)$ & $0(0 \%)$ & 58 \\
\hline MAM & $20(95.2 \%)$ & $0(0 \%)$ & $1(4.8 \%)$ & $0(0 \%)$ & 21 \\
\hline SAM & $15(83.3 \%)$ & $0(0 \%)$ & $2(11.1 \%)$ & $1(5.6 \%)$ & 18 \\
\hline Total & $92(94.8 \%)$ & $1(1 \%)$ & $3(3 \%)$ & $1(1 \%)$ & 97 \\
\hline
\end{tabular}

There is a statistically significant association between complications and severity of malnutrition [more complications are noted in the SAM group and MAM group (p-value 0.023 )]

Table-6: Comorbidities among classification of malnutrition.

\begin{tabular}{|l|l|l|}
\hline & \multicolumn{1}{|c|}{ Anaemia } & \multicolumn{1}{c|}{ No co-morbidities } \\
\hline Normal & $7(12.1 \%)$ & $48(82.2 \%)$ \\
\hline MAM & $4(19 \%)$ & $14(66.7 \%)$ \\
\hline SAM & $1(5.6 \%)$ & $11(61.1 \%)$ \\
\hline Total & 12 & 73 \\
\hline
\end{tabular}

More children with MAM had anaemia (19\%) than SAM and normal groups. Fewer children with normal anthropometry had comorbidities. These data were statistically significant ( $p=0.026)$.

Table 7: Duration of hospital stay among the classification of malnutrition

\begin{tabular}{|l|l|c|c|l|l|l|}
\hline & Number & Mean & SD & Std. Error & Minimum & Maximum \\
\hline Normal & 58 & 6.4828 & 3.02180 & 0.39678 & 1.00 & 18.00 \\
\hline MAM & 21 & 8.2381 & 5.40282 & 1.17899 & 3.00 & 24.00 \\
\hline SAM & 18 & 13.388 & 4.85240 & 1.14372 & 3.00 & 21.00 \\
\hline Total & 97 & 8.1443 & 4.74339 & 0.48162 & 1.00 & 24.00 \\
\hline
\end{tabular}

P-value was 0.005 showing a statistically significant association between the severity of malnutrition and duration of hospital stay being maximum in SAM followed by MAM and then the normal group.

No statistically significant difference in the duration of stay in ICU. 


\section{Discussion}

Diarrhoea and pneumonia contribute to a third of worldwide childhood mortality. Both the infections are part of a vicious cycle of malnutrition and infection. Children who are undernourished are more prone to infections and have a higher morbidity and mortality rate [7]. A study by Christi MJ et al showed an association between complications, morbidities and severity of malnutrition [8]. Even in the present study, the statistically significant association between complications and severity of malnutrition was noted.

In a study by Isanaka et al, it was concluded that on the basis of prevalence of undernutrition, the current global projections of mortality associated with SAM and MAM could be underestimated [9]. Programmes for the management of MAM have not been revised for the past 3 decades unlike those with respect to SAM, and hence needs appropriate and urgent amendments [10].

Nutrition care in children and mother will essentially contribute to national development. According to The Global Nutrition Report, the benefit-to-cost ratio is $16: 1$ for investment in nutrition among 40 middle and low -income countries. Preventing undernutrition at the earliest and throughout life is important [11].

In a study in Bangladesh, among 209 boys and 191 girls with pneumonia and diarrhoea, $17 \%$ were found to have SAM. high prevalence of pneumonia $(62.72 \%)$ and diarrhoea were found in infancy, and in 1-2-year age group [12]. In the present study, SAM was found in $18.5 \%$, which is comparable, even the prevalence of pneumonia (66\%) was comparable. In the present study, more number of girls were undernourished. A positive association was noted between the duration of hospital stay and severity of malnutrition.

Diarrhoea has short-term effects on nutrition and long-term consequences on the growth of the child [12]. In the present study, the prevalence of diarrhoea was same in SAM and MAM group.

In a study by Brown $\mathrm{KH}$ et al, among 100 children admitted for SAM, $90 \%$ had evidence of infection at the time of admission, $75 \%$ had pneumonia, $43 \%$ had diarrhoea and death rate was $21 \%$, the most frequent cause being infections. Mortality was more in younger children [13].
In the present study, there was no mortality and $72.2 \%$ of SAM children had pneumonia, $27.7 \%$ had diarrhoea, while in the MAM group, $71.4 \%$ had pneumonia and $33.3 \%$ had diarrhoea.

Terri J Ballard et al, in their study, concluded that underweight and stunting were positively associated with acute lower respiratory infections and improving nutrition contributed to lowering the incidence of acute lower respiratory infections [14].

Tupasi TE et al, in their study, concluded that the relative risks for morbidity and mortality for both acute upper and lower respiratory tract infections were higher in children with malnutrition compared to normal children [15]. In the present study, $72.2 \%$ of SAM and $71.4 \%$ of MAM had pneumonia which was more than that in the normal group $(67 \%)$.

Chisti MJ et al, in their study, concluded that malnutrition was associated with a significant increase in mortality risk in children with pneumonia. Also, the odds ratio and relative risk were higher for children with SAM than MAM [8]. In the present study, there was no mortality though morbidities were comparable in SAM and MAM group. Anaemia was noted to be more in the MAM group.

In the present study, the complications like sepsis and duration of stay were more in SAM children. SAM significantly increases the risk of under-5 mortality and also indirectly increases mortality by increasing the case fatality rate in infections like diarrhoea and pneumonia. Mortality in children with SAM is essentially the effect of infection [16].

Christi MJ et al, in their study on post-discharge mortality in children with severe malnutrition and pneumonia in Bangladesh among 405 children admitted for SAM and pneumonia, $8.7 \%$ had mortality within 3 months of discharge, among which new respiratory and gastro-intestinal symptoms were common.

Hence, follow-up of the children after discharge from the hospital has a role in early recognition of complications and reducing mortality [17]. In another study by Christi $\mathrm{MJ}$ et al, demographic and socioeconomic status, including over-crowding and smoking were contributory factors to pneumoniarelated deaths. Education and increasing public awareness are necessary means to reduce these risks [18]. 
In a study conducted in South Africa, Bamford et al, analysed the improvements in case fatality rates in under-5 children. Required measures to reduce under-5 mortality include a reduction in mother-tochild HIV transmission, improvement in infant and young child feeding, better immunization coverage, earlier and easier access to health care, the betterment of social and community health as a whole [19].

Jones DK, et al, in their study concluded that along with nutrition, addressing the infection and inflammation plays a key role; along with anthropometric measurements, it is important to assess the child's health in-toto [20].

In a study by Tickell KD et al, children with a MUAC of $<12.5 \mathrm{~cm}$ had more severe diarrhoea and danger signs when compared to better-nourished counterparts. Diarrhoeal pathogens such as cryptosporidium, virulent E.coli, Entamoeba histolytica, Shigella, Salmonella, Campylobacter, Pleisiomonas shigelloides have been associated with acute malnutrition.

However, the higher disease severity is more likely to be due to socio-economic constraints and increased vulnerability associated with acute malnutrition, than due to different pathogenic flora. [21].

According to Williams PCM and Berkley JA, in their study in 2018, it was suggested that irrespective of uncomplicated or complicated SAM, a broadspectrum antibiotic should be used, namely, amoxicillin via oral and parenteral route respectively. All the children in the present study were similarly started with Amoxicillin by parenteral route as per the WHO guidelines [22].

In a systematic review and meta-analysis in 2020, $\mathrm{F}$ 100 was similar in effect to Ready-to-use therapeutic food, prophylactic antibiotic usage had better recovery in terms of disease as well as weight gain; high and low dose vitamin A supplementation were comparable in terms of mortality and gain in weight [23].

In a study in Afghanistan, it was concluded that parental education and income status, availability of safe drinking water, sanitary latrines, hygiene all play a key role in reducing the prevalence of acute nutrition among under-5 children [24]. Hence, in improving the nutritional status in children, national programs, programmatic policies in the betterment of the community in entirety are necessary.
In a study by Manary MJ, on the management of acute moderate and severe malnutrition, the adverse consequences of pneumonia and diarrhoea on physical and intellectual development, and the importance of appropriate timely management to prevent these complications have been reviewed [25].

Hence, if MAM children are neglected, they may later land up in SAM and lead to more mortality due to complications and also prolonged hospital stay leading to a financial burden to the family and nation. Integrated management of MAM and SAM helps in the better recovery rate and good community coverage [26].

Therefore, if concentration on MAM children as much as SAM children in the national programmes the following advantages are gained-

01. Reduce the incidence of Pneumonia and diarrhoea, the 2 leading causes of Under 5 mortality in children.

02. By reducing the burden of SAM, the mortality due to complications like septicemia are prevented.

03. By decreasing the duration of hospital stay in these children (by preventing them from developing SAM), the financial burden is reduced.

Limitations of the present study are that:

01. There was no follow-up of the children to assess their nutritional status and catch-up growth following treatment and prevalence of diarrhoea and pneumonia in the same group of children following nutritional rehabilitation

02. As per the present study was a hospital-based study, the results cannot be generalized to the community.

\section{Conclusions}

The prevalence of diarrhoea and pneumonia, which are the leading causes of under-five mortalities, were found to be same in both children with Moderate Acute Malnutrition and Severe Acute Malnutrition.

Complications and morbidities in MAM are similar to SAM, hence, it is important to diagnose MAM and treat it vigilantly as in SAM. It is important to recognize and monitor MAM which may often go neglected. 


\section{Recommendation}

It is important to monitor and take a necessary intervention to treat MAM as seriously as in SAM both by the treating Paediatrician and in National Health Programmes.

\section{What does this study add to the existing knowledge?}

01. Children with severe acute malnutrition are more prone to Pneumonia and Diarrhoea and their complications. The prevalence of diarrhoea and pneumonia, which are the leading causes of under-five mortalities, were found to be same in both children with Moderate Acute Malnutrition and Severe Acute Malnutrition.

02. Hence, it is important to diagnose MAM and treat it vigilantly as in SAM

\section{Author's contributions}

All the authors contributed to the study. Dr. $\mathbf{M} \mathbf{R}$ Savitha conceived and designed the study and revised the manuscript for important intellectual content. Dr. M R Prashanth designed the study proforma, sample collection process, helped design the study and revised the manuscript. Dr. B. Thanuja collected and compiled the data and drafted the paper. Dr. M R Savitha, Dr. M R Prashanth, Dr. B. Thanuja analysed the data, edited, reviewed and approved the final paper.

\section{Reference}

01. Black RE, Victoria CG, Walker SP, Bhutta Z, Christian $P$, et al. Maternal and child undernutrition and overweight in low-income and middle-income countries. Lancet Maternal and Child Nutrition Series, Lancet. 2013;382(9890)427-451. doi: 10.1016/S0140-6736(13)60937-X [Crossref] [PubMed][Google Scholar]

02. The World Bank. Repositioning Nutrition as Central to Development- A Strategy for Large-Scale Action. Washington, DC- The International Bank for Reconstruction and Development/ The World Bank. 2006. Available at: [Article][Crossref][PubMed] [Google Scholar]

03. International Institute for Population Sciences (IIPS) and ICF. National Family Health Survey (NFHS-4), 2015-16- India. Mumbai- IIPS. 2017. Available at: [Article][Crossref][PubMed][Google Scholar
04. World health Organization. Revised WHO classification and treatment of pneumonia in children at health facilities- evidence summaries. WHO. 2014. Available at: [Article][Crossref] [PubMed][Google Scholar]

05. World Health Organization. Updates on the management of severe acute malnutrition in infants and children. Geneva- WHO. 2013. Available At: [Article][Crossref][PubMed][Google Scholar]

06. WHO (World Health Organization). Supplementary Foods for the management of Moderate acute malnutrition in infants and children 6-59 months of age. Technical note, WHO, Geneva. 2012. Available at: [Article][Crossref][PubMed] [Google Scholar]

07. Schlaudecker EP, Steinhoff MC, Moore SR. Interactions of diarrhea, pneumonia, and malnutrition in childhood- recent evidence from developing countries. Curr Opin Infect Dis. 2011;24(5)496-502. doi: 10.1097/QCO.0b013e328349287d [Crossref] [PubMed][Google Scholar]

08. Chisti MJ, Tebruegge M, La Vincente S, Graham SM, Duke T. Pneumonia in severely malnourished children in developing countries- mortality risk, etiology and validity of WHO clinical signs- a systematic review. Trop Med Int Health. 2009;14(10)1173-1189. doi: 10.1111/j.13653156.2009.02364.x [Crossref][PubMed][Google Scholar]

09. Isanaka S, Grais F R, Briend A, Checchi F. Estimates of the duration of untreated acute malnutrition in children from Niger. Am J Epidemiol. 2011;173(8)932-940. doi: 10.1093/aje/kwq436 [Crossref][PubMed][Google Scholar]

10. WHO - Moderate Malnutrition. Available from: [Article][Crossref][PubMed][Google Scholar]

11. National Nutrition Strategy-NITI Aayog. 2015. Available from: [Article][Crossref][PubMed][Google Scholar]

12. Rahman SS, Khatun A, Azhar BS, Rahman $H$, Hossain S. A Study on the Relationship between Nutritional Status and Prevalence of Pneumonia and Diarrhoea among Preschool Children in Kushtia. Pediatr Res Int J. 2014. doi: 10.5171/2014.805309 [Crossref][PubMed][Google Scholar] 
13. Brown $\mathrm{KH}$, Gilman $\mathrm{RH}$, Gaffar A, Alamgir SM, Strife $J \mathrm{~L}$, et al. Infections associated with severe protein-calorie malnutrition in hospitalized infants and children. Nut Res. 1981;1(1)33-46. Doi: 10.1016/S0271-5317(81)80006-1

[Crossref]

[PubMed][Google Scholar]

14. Ballard TJ, Neumann CG. The effects of malnutrition, parental literacy and household crowding on acute lower respiratory infections in young Kenyan children. J Trop Pediatr. 1995;41(1)813. doi: 10.1093/tropej/41.1.8 [Crossref][PubMed] [Google Scholar]

15. Tupasi TE, Mangubat NV, Sunico ME, Magdangal DM, Navarro EE, et al. Malnutrition and acute respiratory tract infections in Filipino children. Rev Infect Dis. 1990;12(8)S1047-S1054. doi: 10.1093/clinids/12.Supplement_8.S1047 [Crossref] [PubMed][Google Scholar]

16. Jones K D, Berkley J A. Severe acute malnutrition and infection. Paediatr Int Child Health. 2014;34(1)1-29. doi: 10.1179/2046904714Z.000000000218 [Crossref] [PubMed][Google Scholar]

17. Chisti MJ, Graham SM, Duke T, Ahmed T, Faruque ASG, et al. Post-discharge mortality in children with severe malnutrition and pneumonia in Bangladesh. PLoS One. 2014;9(9)e107663. doi: 10.1371/journal.pone.0107663 [Crossref][PubMed] [Google Scholar]

18. Christi MJ, Duke $T$, Robertson CF, Ahmed $T$, Faruque ASG, et al. Co-morbidity- exploring the clinical overlap between pneumonia and diarrhoea in a hospital in Dhaka, Bangladesh. Ann Trop Paediatr. 2011;31(4)311-319. doi: 10.1179/1465328111Y.0000000033 [Crossref] [PubMed][Google Scholar]

19. L Bamford, P Barron, S Kauchali, N Dlamini. Inpatient case fatality rates improvements in children under 5- Diarrhoeal disease, pneumonia and severe acute malnutrition. S Afr Med J. 2018;108(3 Suppl 1)533-537. doi: 10.7196/SAMJ. 2018.v108i3.12772 [Crossref][PubMed][Google Scholar]
20. Jones KD, Thitiri J, Ngari M, Berkley JA. Childhood malnutrition- toward an understanding of infections, inflammation, and antimicrobials. Food Nutr Bull. 2014;35(2)64-70. doi: 10.1177/15648265140352S110 [Crossref][PubMed] [Google Scholar]

21. Tickell KD, Pavlinac PB, John-Stewart G, Denno DM, Richardson BA, et al. Impact of childhood nutritional status on pathogen prevalence and severity of acute diarrhoea. Am J Trop Med Hyg. 2017;97(5)1337-1334. doi: 10.4269/ajtmh.17-0139 [Crossref][PubMed][Google Scholar]

22. Williams PCM, Berkley JA. Guidelines for the treatment of severe acute malnutrition- a systematic review of the evidence for antimicrobial therapy. Paediatr Int child health. 2018;38(1)S3249. doi: 10.1080/20469047.2017.1409453 [Crossref][PubMed][Google Scholar]

23. Das JK, Salam RA, Saeed M, Kazmi FA, Bhutta ZA. Effectiveness of interventions for managing acute malnutrition in children under five years of age in low-income and middle-income countries- a systematic review and meta-analysis. Nutrients. 2020;12(1)116. doi: 10.3390/nu12010116 [Crossref][PubMed][Google Scholar]

24. Frozanfar MK, Yoshida Y, Yamamoto E, Reyer JA, Dalil $S$, et al. Acute malnutrition among under-five children in Faryab, Afghanistan- prevalence and causes. Nagoya J Med Sci. 2016;78(1)41-53. [Crossref][PubMed][Google Scholar]

25. Manary MJ, Sandige HL. Management of acute moderate and severe childhood malnutrition. BMJ. 2008;337;a2180. doi: 10.1136/bmj.a2180 [Crossref][PubMed][Google Scholar]

26. Maust A, Koroma AS, Abla C, Molokwu N, Ryan $\mathrm{KN}$, et al. Severe and moderate malnutrition can be successfully managed with an integrated protocol in Sierra Leone. J Nutr. 2015;145(11)2604-2609. doi: 10.3945/jn.115.214957 [Crossref][PubMed][Google Scholar] 